\title{
Influência da concentração de ácido acético presente no licor pirolenhoso na anodização de nióbio
}

\author{
Luã Tainachi Mueller \\ Keila Vieira Oliveira \\ Fernando Dal Pont Morisso \\ Sandra Raquel Kunst ${ }^{1}$ \\ Carlos Leonardo Pandolfo Carone \\ Cláudia Trindade Oliveira ${ }^{1 *}$ (1)
}

\section{Resumo}

O licor pirolenhoso é um líquido obtido da condensação de fumaças e vapores resultantes da decomposição da madeira por pirólise controlada. Neste trabalho foi utilizado o licor pirolenhoso da Acácia Negra. O licor é constituído de compostos orgânicos, cujo componente majoritário é o ácido acético, com aproximadamente 4\%. Com isso, o objetivo deste trabalho foi verificar se o ácido acético é o principal agente na anodização de nióbio em licor pirolenhoso. Para tanto, amostras de nióbio foram anodizadas em ácido acético nas mesmas condições já testadas para o licor pirolenhoso. As anodizações foram feitas com aplicação de $18,7 \mathrm{~mA} / \mathrm{cm}^{2}, 100 \mathrm{~V}$, por $300,600,1800$ e 3600 s. O nióbio anodizado foi comparado nos dois eletrólitos (ácido acético e licor pirolenhoso) quanto às taxas de crescimento da camada de óxido por anodização, coloração, morfologia e espessura. Os resultados apontaram semelhanças em todos os testes realizados, indicando que provavelmente o ácido acético é o principal agente na anodização com licor pirolenhoso.

Palavras-chave: Anodização; Nióbio; Licor pirolenhoso.

\section{Influence of acetic acid concentration on pyrolenous liquor in niobio anodization}

\begin{abstract}
Pyroligneous liquor is a liquid obtained from the condensation of fumes and vapors resulting from the decomposition of wood by controlled pyrolysis. In this work, Acacia Negra's pirolenhoso liquor was used. The liquor consists of organic compounds, the major component of which is acetic acid, with approximately $4 \%$. Thus, the objective of this work was to verify whether acetic acid is the main agent in the anodization of niobium in pyroligneous liquor. For that, niobium samples were anodized in acetic acid under the same conditions already tested for the pyroligneous liquor. Anodizations were made with the application of $18.7 \mathrm{~mA} / \mathrm{cm}^{2}, 100 \mathrm{~V}$, for $300,600,1800$ and $3600 \mathrm{~s}$. The anodized niobium was compared in the two electrolytes (acetic acid and pyroligneous liquor) regarding the growth rates of the oxide layer by anodizing, coloring, morphology and thickness. The results showed similarities in all tests performed, indicating that probably acetic acid is the main agent in anodizing with pyroligneous liquor.
\end{abstract}

Keywords: Anodization; Nióbium; Pyrolignous liquor.

\section{Introdução}

O licor pirolenhoso é também conhecido como ácido pirolenhoso, líquido pirolenhoso, extrato pirolenhoso ou vinagre de madeira. Ele é um líquido resultante da condensação da fumaça produzida durante a decomposição da madeira por pirólise controlada, originada da fabricação de carvão. Atualmente, os principais países produtores de licor pirolenhoso são o Japão, China, Indonésia, Malásia, Brasil e Chile, incluindo outros no Sudeste Asiático e na América do Sul. No Brasil, a maioria da madeira empregada para este fim é proveniente do eucalipto, pinus, bambu e acácia negra no Rio Grande do Sul, sendo este o estado que mais cultiva acácia negra no Brasil. Estudos feitos na

${ }^{I} I C E T$ - Instituto de Ciências Exatas e Tecnológicas, Universidade Feevale, Novo Hamburgo, RS, Brasil.

*Autor correspondente: ctofeevale@gmail.com

2176-1523 (C) 2021. Mueller et al. Publicado pela ABM. Este é um artigo publicado em acesso aberto (Open Access) sob a licença Creative Commons Attribution, que permite uso, distribuição e reprodução em qualquer meio, sem restrições desde que o trabalho original seja corretamente citado. 
Universidade Feevale avaliaram os parâmetros cinéticos da decomposição da madeira de acácia-negra (Acacia mearnsii De Wild.) plantada no Rio Grande do Sul [1].

A madeira é utilizada na fabricação de celulose, aglomerado e obtenção de energia pela produção de carvão vegetal. Já o licor pirolenhoso, por apresentar características como antifungicida e biopesticida, é bastante utilizado na agricultura. Estudos relatam a aplicação do licor na eliminação de ácaros na citricultura. Neste caso, o licor foi utilizado em substituição a pesticidas sintéticos que não podem ser utilizados na agricultura orgânica. Na área alimentícia e agronômica, o licor pirolenhoso vem atraindo a atenção de pesquisadores e técnicos, como alternativa de um produto natural de fonte renovável e sustentável [2].

O licor pirolenhoso é constituído de vários compostos fenólicos, sendo que o predominante é o ácido acético. $\mathrm{O}$ extrato pirolenhoso extraído de pinus filtrado após a decantação é composto de 80 a $90 \%$ de água e 10 a $20 \%$ de compostos orgânicos, sendo o principal o ácido acético. Em análises de licor pirolenhoso obtido da casca do durião, os autores observaram que o ácido acético é o constituinte majoritário (40\%) em comparação aos demais componentes orgânicos [3].

A predominância de ácido acético no licor pirolenhoso pode ser uma alternativa para exploração deste líquido em outros segmentos industriais além da agricultura. $\mathrm{Na}$ área de tratamento de superfíce para proteção contra corrosão poucos estudos têm sido feitos com o ácido acético. Neste segmento industrial, o ácido acético pode ser visto como uma alternativa ambientalmente correta, uma vez que seu descarte é extremamente fácil comparado a outros ácidos utilizados em galvanoplastia [2,3].

O licor pirolenhoso melhora a qualidade dos gases lançados na atmosfera e pode ser lançado ao meio ambiente sem causar prejuízos, podendo ser utilizado como eletrólito em indústria galvânica. Nesse contexto, aplicação do licor pirolenhoso no processo de anodização de metais pode ser vantajoso como eletrólito ambientalmente correto. Em um trabalho recente, Sá et al. [2], apontaram o uso do licor na anodização do metal nióbio.

O nióbio por sua vez é um metal com excelentes propriedades e características, apresentando atualmente uma grande utilidade para o mercado. Os estudos técnicos e científicos aumentam em relação ao nióbio devido a sua grande resistência a corrosão e a sua aplicabilidade na indústria, sendo que o Brasil possui a maior reserva mundial deste metal [4-6].

$\mathrm{Na}$ anodização de nióbio com licor pirolenhoso, observou-se a formação de óxido barreira com coloração rosa, a qual apresenta aproximadamente $300 \mathrm{~nm}$ de espessura, demonstrando uma alternativa ambientalmente correta para a indústria galvânica [1]. No entanto, embora o constituinte majoritário do licor pirolenhoso é o ácido acético (4\%), não se pode afirmar se a anodização com nióbio é governada por este ácido ou pelo restante dos compostos presentes no licor $[6,7]$.
Portanto, este trabalho mostra uma comparação entre o processo de anodização em nióbio com o uso do ácido acético (eletrólito orgânico) na mesma proporção da quantidade deste ácido na composição do licor pirolenhoso, para anodização com licor pirolenhoso foi diluído $50 \%$ do licor pirolenhoso em água e para anodização em ácido acético foi $2 \%$ do ácido acético diluído em água. $\mathrm{O}$ intuito do deste artigo é verificar a influência do ácido acético na anodização de nióbio com uso de licor pirolenhoso.

\section{Materiais e métodos}

\subsection{Preparação das amostras}

Para realização deste trabalho foi utilizado como material uma chapa de $\mathrm{Nb}$ puro $(99,5 \%)$, fornecida pela Companhia Brasileira de Metalurgia e Mineração, para o processo de anodização. A partir do Nióbio fornecido, foram cortadas as amostras para utilizar nos processos de anodização, com dimensões de $1,5 \times 2,5 \mathrm{~cm}$.

A partir do Nióbio fornecido pela CBMM, foram cortadas as amostras nas dimensões desejadas $1,5 \times 2,5 \mathrm{~cm}$, as quais foram lixadas com lixas d'água de carboneto de silício ( $\mathrm{SiC})$, iniciando na granulometria \#220 até a granulometria \#4000. Em um dos lados da amostra foi fixado fio de cobre permitindo o contato elétrico, seguido de isolamento com resina epoxídica para que não interferisse no processo de anodização, sendo que cada amostra ficou com uma superfície exposta de $3,8 \mathrm{~cm}^{2}$ para anodização. Durante o processo de anodização em modo galvanostático foi observado aumento de potencial semelhante em todas as condições de anodização o que garante a reprodutibilidade do processo.

\subsection{Anodização}

Antes da realização do processo de anodização as amostras foram decapadas durantes 5 segundos em solução aquosa composta por $40 \%$ de ácido fluorídrico (HF) e $60 \%$ de ácido nítrico $\left(\mathrm{HNO}_{3}\right)$, com agitação. Após decapadas, as amostras foram lavadas em água deionizada. $O$ equipamento utilizado foi uma fonte de tensão $\times$ corrente ( $300 \mathrm{~V}-500 \mathrm{~mA}$ ) ligado a um computador com software proprietário para obtenção dos resultados.

A anodização teve o ácido acético como o eletrólito, com $2 \%$ (em comparação com o licor pirolenhoso, que foi diluído $50 \%$ em água deionizada) em volume diluído em água deionizada. O processo teve como característica o modo galvanostático com aplicação de densidade de corrente de $18,7 \mathrm{~mA} / \mathrm{cm}^{2}$ até que a tensão atingisse $100 \mathrm{~V}$, passando para modo potenciostático, por diferentes tempos, 300, 600, 1800 e 3600s. No processo de anodização o ânodo era a amostra de nióbio e o cátodo era uma grade de platina.

Durante o processo de anodização foram gerados gráficos de transientes de potencial e densidade de corrente. A 
Tabela 1 mostra a nomenclatura para as amostras analisadas e as características utilizadas para o processo de anodização.

\subsection{Caracterização das amostras}

As amostras foram analisadas de acordo com os transientes de anodização, obtidas por meio do software do computador ligado a fonte de tensão e a partir destes dados foram elaborados os gráficos para melhor visualização dos dados. Após o processo de anodização as amostras foram analisadas de acordo com a sua coloração, morfologia do óxido e foi feita medida de espessura por meio do microscópio eletrônico de varredura (MEV Jeol, modelo JSM-6510LV).

\section{Resultados e discussão}

\subsection{Transientes de potencial e densidade de corrente $\times$ tempo de anodização}

A Figura 1 mostra os transientes de potencial e densidade de corrente das amostras de nióbio anodizadas em $0,2 \%$ de ácido acético em tempos diferentes. A Figura 2 , mostra o licor pirolenhoso anodizado nas mesmas condições que o ácido acético. Para efeito de comparação os transientes foram plotados até $50 \mathrm{~s}$.

Tabela 1. Nomenclatura e características de anodização

\begin{tabular}{cccc}
\hline Amostra & Eletrólito & $\begin{array}{c}\text { Densidade de corrente } \\
\mathbf{m A} / \mathbf{c m}^{\mathbf{2}}\end{array}$ & Tensão V \\
\hline $\mathrm{Nb} 300$ & $2 \%$ Ácido acético & 18,7 & 100 \\
$\mathrm{Nb} 600$ & $2 \%$ Ácido acético & 18,7 & 100 \\
$\mathrm{Nb} 1800$ & $2 \%$ Ácido acético & 18,7 & 100 \\
$\mathrm{Nb} 3600$ & $2 \%$ Ácido acético & 18,7 & 1800 \\
\hline
\end{tabular}
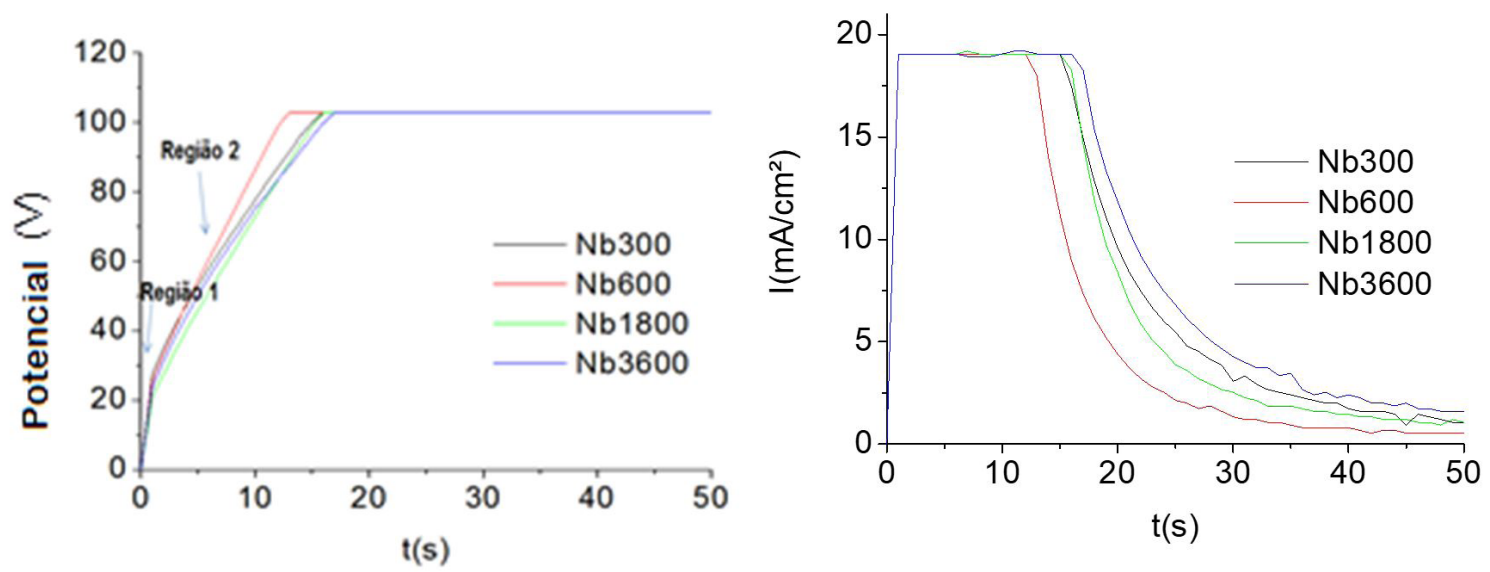

Figura 1. Transientes de potencial $\times$ densidade de corrente $\times$ para as amostras de nióbio anodizadas em $2 \%$ ácido acético.
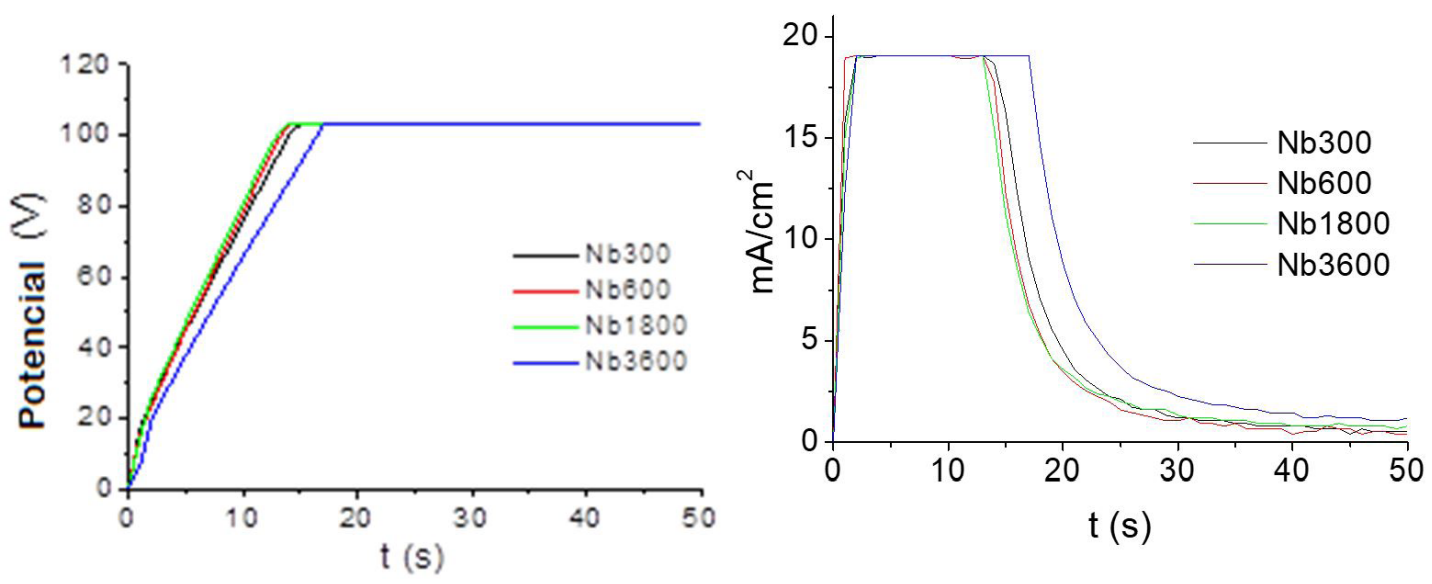

Figura 2. Transientes de potencial $\times$ densidade de corrente $\times$ para as amostras de nióbio anodizadas em licor pirolenhoso [1]. 
Observa-se que as amostras anodizadas em ácido acético apresentam comportamento semelhante às anodizadas em licor pirolenhoso. Assim mesmo, os transientes tanto em ácido acético como em licor pirolenhoso são semelhantes entre si, independentemente do tempo de anodização, o que demonstra que o processo de anodização ocorre de forma semelhante nos dois meios e é possível que estes comportamentos concordantes ocorram em função da presença majoritária de ácido acético no licor pirolenhoso.

Nos dois eletrólitos se observa aumento do potencial em função do tempo até atingir $100 \mathrm{~V}$ e a partir deste momento o potencial se mantém constante. Ao atingir $100 \mathrm{~V}$, ocorre uma queda nos valores de densidade de corrente até próximo de zero, comportamento característico de formação de óxido durante a anodização. Como o eletrólito não ataca quimicamente o óxido, a característica observada nos transientes é de formação de óxido barreira. A inclinação da curva nos transientes de potencial é conhecida como taxa de crescimento de óxido $(\partial \mathrm{V} / \partial \mathrm{t})$ e é limitada pelo potencial aplicado [8].

Observa-se nas Figuras 1 e 2 nos transientes de potencial, que as amostras anodizadas nos dois eletrólitos apresentam duas regiões distintas, uma com maior $\partial \mathrm{V} / \partial \mathrm{t}$ na região 1 , nos segundos iniciais de anodização. E outra, região 2, que demonstra diminuição do valor de $\partial \mathrm{V} / \partial \mathrm{t}$ com o tempo de anodização. Os valores de $\partial \mathrm{V} / \partial \mathrm{t}$ para as duas regiões das amostras anodizadas em ácido acético e em licor pirolenhoso estão mostradas nas Tabelas 2 e 3, respectivamente. Apesar das amostras serem anodizadas em tempos diferentes, o início do processo de anodização é semelhante, o que comprova a reprodutibilidade do processo. Portanto, as médias e desvio padrão das Tabelas 1 e 2 referem-se às taxas de crescimento dos óxidos que são independentes do tempo de anodização.

Observa-se na região 1 , que a taxa de crescimento das amostras anodizadas em ácido acético é maior do que

Tabela 2. Taxa de crescimento de óxidos $(\partial \mathrm{V} / \partial \mathrm{t})$ nas Regiões 1 e 2 de acordo com os transientes da Figura 1, das amostras de nióbio anodizadas em $2 \%$ de ácido acético

\begin{tabular}{ccc}
\hline Amostra & $\partial \mathbf{V} / \partial \mathbf{t}$ na região 1 & $\partial \mathbf{V} / \partial \mathbf{t}$ na região 2 \\
\hline Nb300 & $28 \mathrm{~V} / \mathrm{s}$ & $5,6 \mathrm{~V} / \mathrm{s}$ \\
$\mathrm{Nb600}$ & $27 \mathrm{~V} / \mathrm{s}$ & $7,1 \mathrm{~V} / \mathrm{s}$ \\
$\mathrm{Nb} 1800$ & $22 \mathrm{~V} / \mathrm{s}$ & $5,5 \mathrm{~V} / \mathrm{s}$ \\
$\mathrm{Nb3600}$ & $23 \mathrm{~V} / \mathrm{s}$ & $5,1 \mathrm{~V} / \mathrm{s}$ \\
Média + Desvio Padrão & $25 \pm 2,94$ & $5,8 \pm 0,877 \mathrm{~V} / \mathrm{s}$ \\
\hline
\end{tabular}

Tabela 3. Taxa de crescimento de óxidos $(\partial \mathrm{V} / \partial \mathrm{t})$ nas Regiões 1 e 2 de acordo com os transientes da Figura 2, das amostras de nióbio anodizadas em $4 \%$ de licor pirolenhoso [1]

\begin{tabular}{ccc}
\hline Amostra & $\partial \mathbf{V} / \partial \mathbf{t}$ na região 1 & $\partial \mathbf{V} / \partial \mathbf{t}$ na região 2 \\
\hline $\mathrm{Nb300}$ & $18,67 \mathrm{~V} / \mathrm{s}$ & $6,1 \mathrm{~V} / \mathrm{s}$ \\
$\mathrm{Nb600}$ & $17,33 \mathrm{~V} / \mathrm{s}$ & $6,6 \mathrm{~V} / \mathrm{s}$ \\
$\mathrm{Nb} 1800$ & $17,83 \mathrm{~V} / \mathrm{s}$ & $6,5 \mathrm{~V} / \mathrm{s}$ \\
$\mathrm{Nb} 3600$ & $10,25 \mathrm{~V} / \mathrm{s}$ & $5,2 \mathrm{~V} / \mathrm{s}$ \\
Média + Desvio Padrão & $16,02 \pm 3,88 \mathrm{~V} / \mathrm{s}$ & $6,09 \pm 0,64 \mathrm{~V} / \mathrm{s}$ \\
\hline
\end{tabular}

em licor pirolenhoso. No entanto, na região 2, as taxas de crescimento são semelhantes para os dois eletrólitos.

O comportamento observado nos segundos iniciais do processo de anodização, caracterizando a região 1, possivelmente pode estar associado às reações de interface da dupla camada elétrica. A estrutura inteira da dupla camada elétrica depende de fatores como o grau de agitação da solução, a presença de outros íons além de $\mathrm{Me}^{\mathrm{z}}$ e em qual concentração.

Por outro lado, sabe-se que o ácido acético, $\mathrm{CH}_{3} \mathrm{COOH}$, é um ácido fraco que, quando dissolvido em água, ioniza-se em íons hidrônio $\left(\mathrm{H}_{3} \mathrm{O}^{+}\right)$e íons acetatos $\left(\mathrm{CH}_{3} \mathrm{COO}^{-}\right)$, conforme a Equação 1.

$$
\mathrm{CH}_{3} \mathrm{COOH}+\mathrm{H}_{2} \mathrm{O} \rightleftharpoons \mathrm{H}_{3} \mathrm{O}^{+}+\mathrm{CH}_{3} \mathrm{COO}^{-}
$$

Assim, quando o metal é mergulhado na solução de ambos os eletrólitos, as cargas negativas alinham-se no metal e as cargas positivas (provenientes do eletrólito) alinham-se na superfície do metal. Quando o processo de anodização é iniciado com eletrólito pirolenhoso, o menor $\partial \mathrm{V} / \partial \mathrm{t}$ na região $1 \mathrm{em}$ comparação ao do ácido acético pode ser explicado pela presença de compostos orgânicos existentes do eletrólito pirolenhoso além dos íons acetato $\left(\mathrm{CH}_{3} \mathrm{COO}^{-}\right)$, os quais podem ser adsorvidos na superfície do metal assim que o nióbio é mergulhado em solução, antes do início da anodização e que dificultam o acesso dos íons $\mathrm{O}^{-2}$ à superfície do metal (Figura 3 ).

Com o início e o decorrer da anodização, observa-se uma diminuição em $\partial \mathrm{V} / \partial \mathrm{t}$. Neste caso, supõem-se que os acetatos presentes nos dois eletrólitos concorram com os íons $\mathrm{O}^{-2}$ e sejam responsáveis por essa redução de $\partial \mathrm{V} / \partial \mathrm{t}$ na região 2 (Figura 4 ).

Para que a camada de óxido cresça durante o processo de anodização, é necessário que os íons oxigênio migrem para a superfície do metal. Como existem acetatos disponíveis na solução em ambos os eletrólitos, estes também migrariam para a superfície do metal, ocupando espaço na superfície do nióbio dificultando o acesso dos íons oxigênio ao metal. Além disso, no eletrólito pirolenhoso, existem outros compostos orgânicos que dificultam o acesso dos íons oxigênio à superfície metálica, o que reduziria a taxa de crescimento do óxido.

No entanto, como a molécula de acetato é maior em volume do que o íon oxigênio, este íon conseguiria alcançar a superfície do nióbio, mas com menor frequência do que em um eletrólito ácido usual, o que explicaria a diminuição do valor de $\partial \mathrm{V} / \partial \mathrm{t}$ encontrado na região 2 quando comparado com outros ácidos. Porém, no eletrólito pirolenhoso, existem outras moléculas orgânicas também adsorvidas na superfície do metal que dificultam o processo ainda mais, o que justifica os comportamentos observados.

Marcolin et al. [9] anodizaram nióbio em 1M ácido acético, aplicando $20 \mathrm{~mA} / \mathrm{cm}^{2}$ e observaram somente uma região com $\partial \mathrm{V} / \partial \mathrm{t}$ de $3,45 \mathrm{~V} / \mathrm{s}$. Os autores observaram que o aumento da densidade de corrente aumenta o valor de 
a)

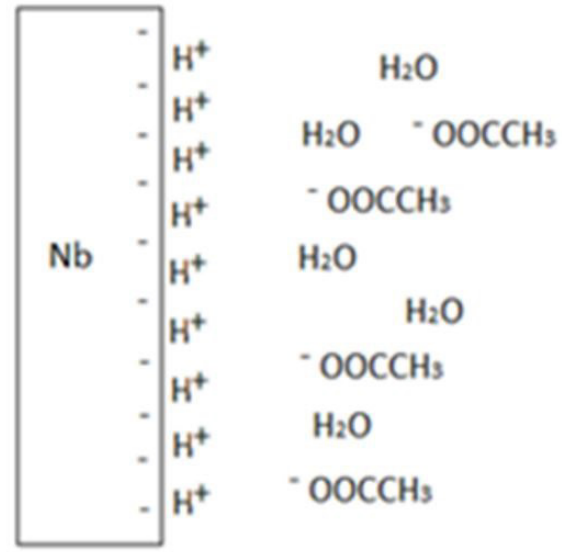

Nióbio mergulhado no eletrólito ácido acético antes do início do processo de anodizaçăo.

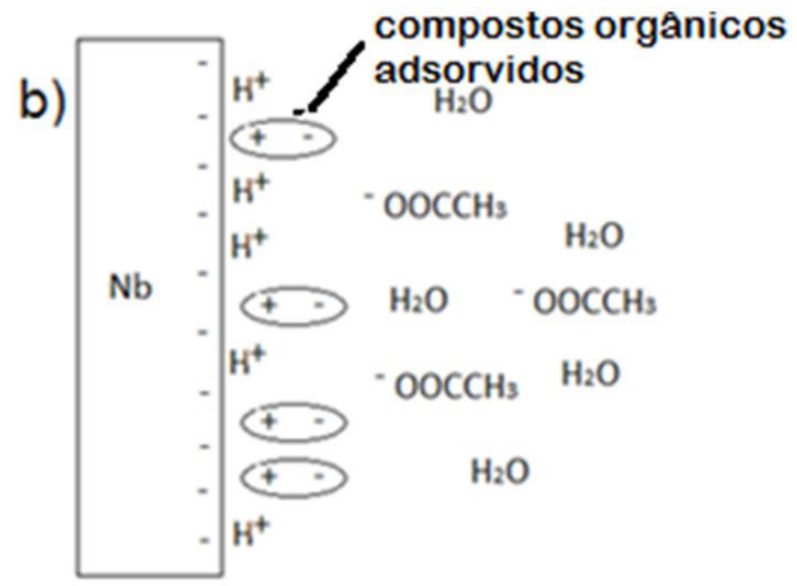

Nióbio mergulhado no eletrólito pirolenhosos antes do início do processo de anodizaçăo.

Figura 3. Esquema do momento antes do início do processo de anodização em ambos os eletrólitos, ácido acético (a) e licor pirolenhoso (b).

a)

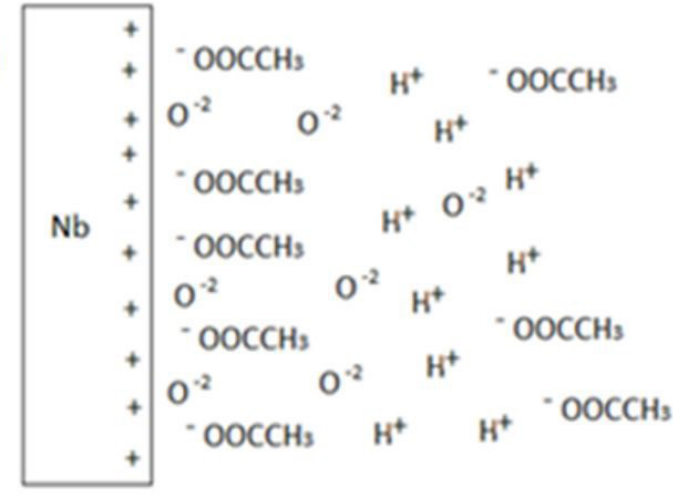

Processo de anodizaçăo iniciado com íons oxigênio competindo com ions acetato pela superficie do metal no eletrólito ácido acético.

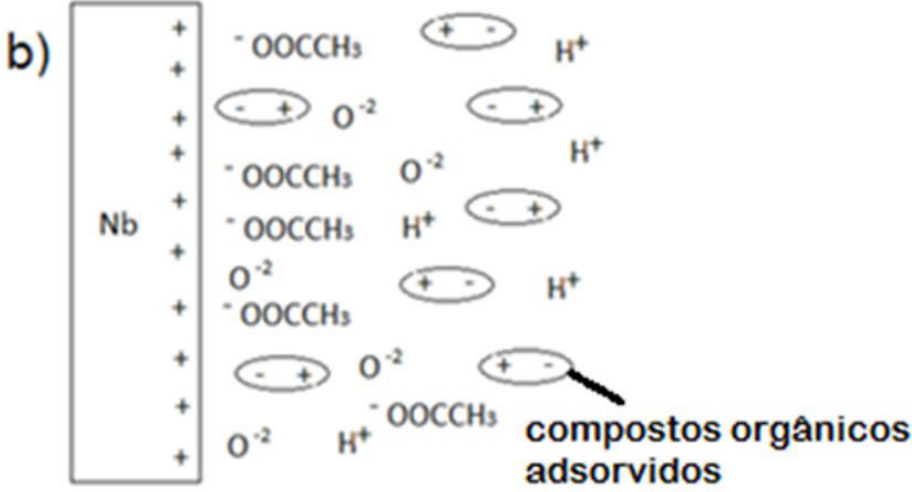

Processo de anodizaçăo iniciado com íons oxigênio competindo com íns acetato e outros compostos orgânicos presentes no eletrólito pirolenhoso, pela superfice do metal.

Figura 4. Esquema do processo de anodização ocorrendo nos dois eletrólitos, ácido acético (a) e licor pirolenhoso (b).

$\partial \mathrm{V} / \partial \mathrm{t}$, originando óxidos com maior quantidade de defeitos estequiométricos. No caso deste trabalho, $2 \%$ em volume de ácido acético representam $0,35 \mathrm{M}$ de ácido acético, ou seja, aproximadamente um terço do que o citado pelos autores Marcolin et al. [9]. Os valores encontrados pelos autores concordam com o exposto neste trabalho, ou seja, uma menor quantidade de acetatos em 0,35 M de ácido acético, permitiria uma maior taxa de crescimento $(\partial \mathrm{V} / \partial \mathrm{t})$, devido a menor quantidade de acetatos adsorvidos na superfície do metal.

Após o processo de anodização as amostras de nióbio adquirem uma coloração diferente na superfície anodizada, a Figura 5 mostra as fotografias do nióbio após o processo de anodização em ácido acético e em licor pirolenhoso.

Durante o processo de anodização as amostras adquirem uma coloração rosa, começando com um tom de rosa mais claro até um tom de rosa mais escuro (quase roxo), com o aumento do tempo de anodização. Observa-se que a variação de coloração das amostras é semelhante para os dois eletrólitos no mesmo tempo de anodização, o que pode ser um indicativo de que os compostos orgânicos existentes no licor pirolenhoso não participam de forma significativa da reação de anodização, sendo o ácido acético o principal responsável pelo crescimento do óxido.

A variação na coloração está geralmente associada à quantidade de óxido presente na superfície [2]. Quando as amostras apresentam uma coloração mais escura durante o processo de anodização barreira, tendendo ao cinza, geralmente se observa a ocorrência de sparking, o que não ocorreu neste trabalho [10]. 


\subsection{Análise da morfologia e seção transversal obtida ao MEV}

A Figura 6 mostra as micrografias obtidas por MEV em vista de topo das amostras de nióbio anodizadas em ácido acético.

Observa-se que todas as amostras anodizadas apresentam defeitos superficiais independentemente do tempo de anodização. Isto está de acordo com a coloração rosa observada em todas as amostras. No entanto, como o óxido formado em menor tempo (amostra $\mathrm{Nb} 300$ ) apresenta matiz com coloração mais fraca em comparação às outras amostras, os defeitos superficiais observados são oriundos do metal base [10], indicando que o óxido possivelmente é bastante fino. De acordo com alguns autores, o aumento do tempo de anodização não apenas aumenta a espessura do

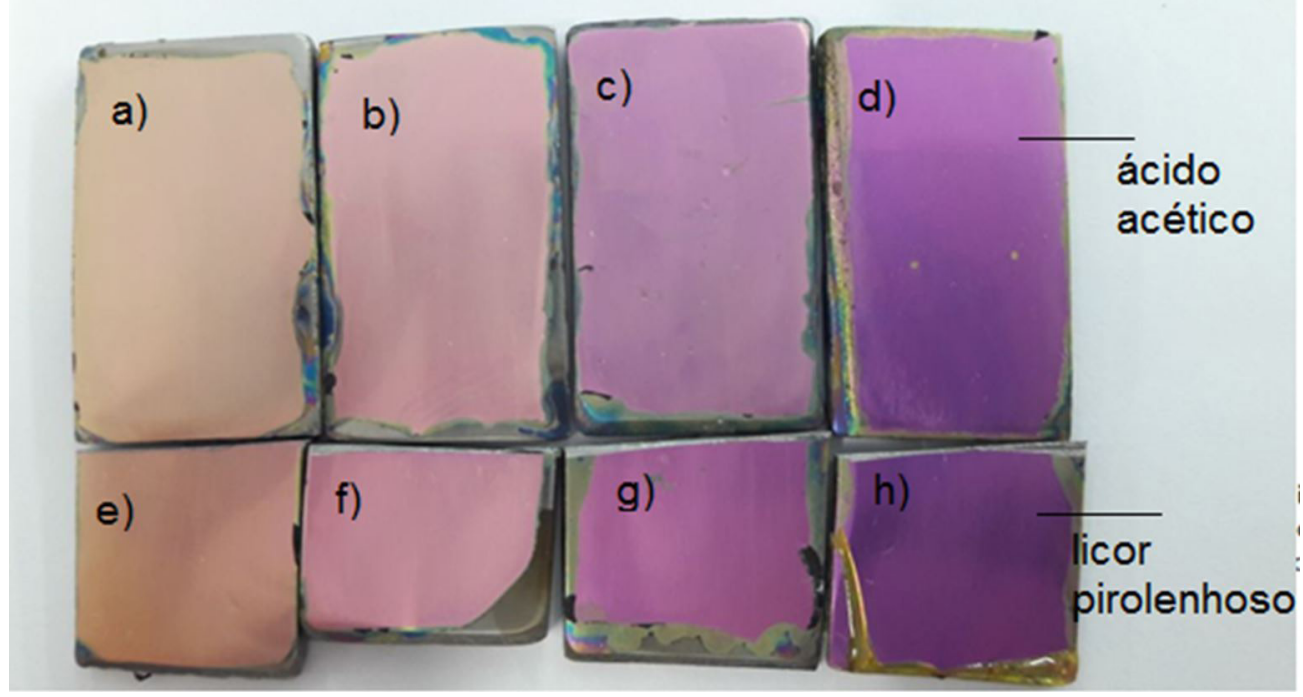

Figura 5. Fotografias das amostras de nióbio anodizadas em ácido acético (a) 300; (b) 600; (c) 1800; (d) 3600s e em licor pirolenhoso (abaixo) (e) 300 ; (f) 600; (g) 1800; e (h)3600s.
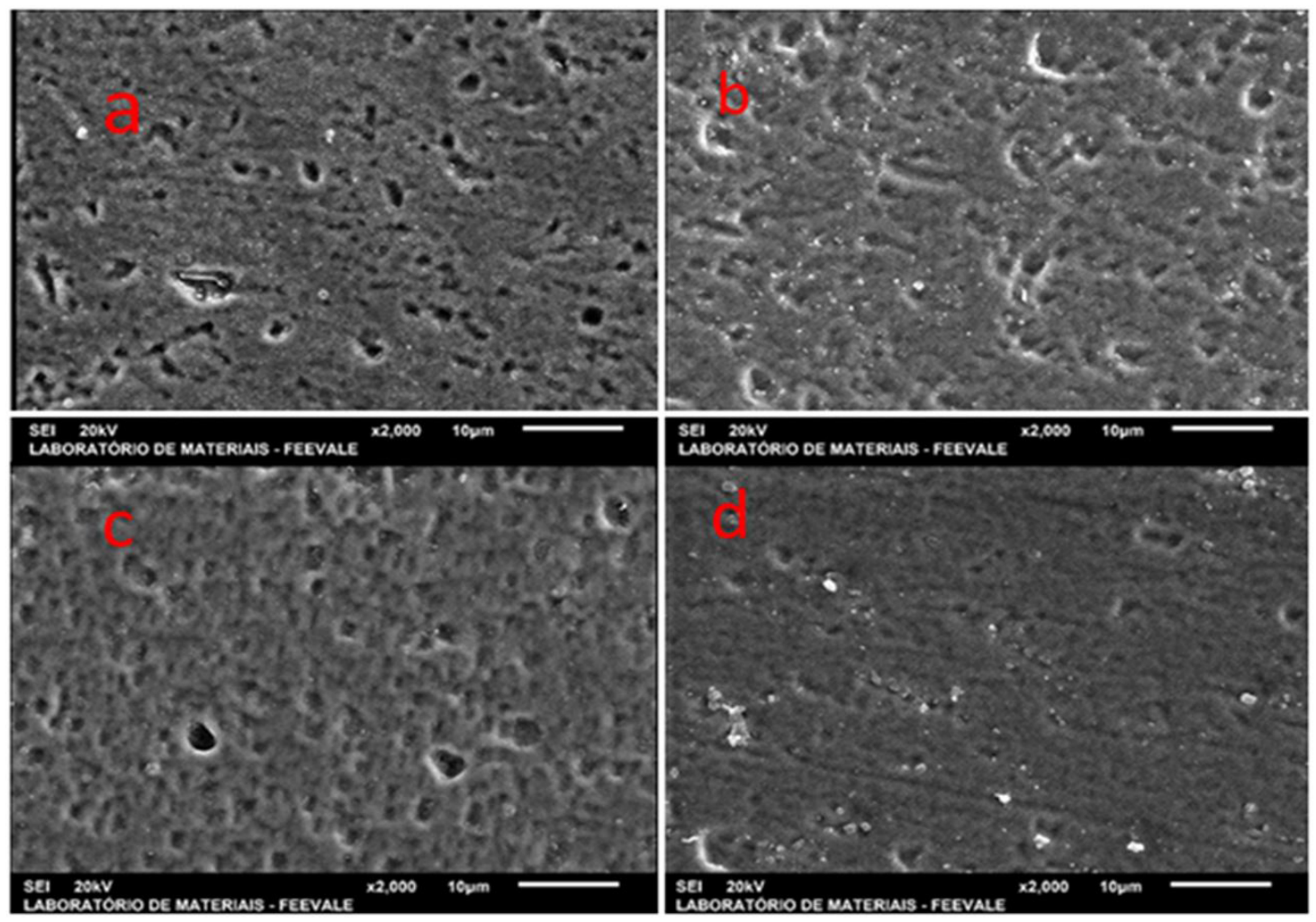

Figura 6. Micrografias obtidas ao MEV em vista de topo das amostras de nióbio anodizadas em ácido acético por tempos de (a) 300s; (b) 600s; (c) $1800 \mathrm{~s}$; e (d) $3600 \mathrm{~s}$. 
óxido, mas diminui a quantidade de defeitos estequiométricos originados durante a anodização [11], o que explicaria a coloração mais intensa (Nb3600), sem a mudança de cor rosa. A Figura 7 mostra as micrografias obtidas por MEV em vista de topo das amostras de nióbio anodizadas em licor pirolenhoso.

Observa-se para o licor pirolenhoso defeitos na superfície das amostra anodizadas independentemente do tempo de anodização (Figura 7). Assim como no ácido acético, o licor pirolenhoso também apresentou coloração rosa, com variação das matizes, indicando que os defeitos superficiais são originados do metal base, com espessura de óxido bastante fina.

Os defeitos superficiais das amostras anodizadas, Figura 8, não são indicativos da formação de óxidos porosos, os quais se formam em eletrólitos que atacam quimicamente
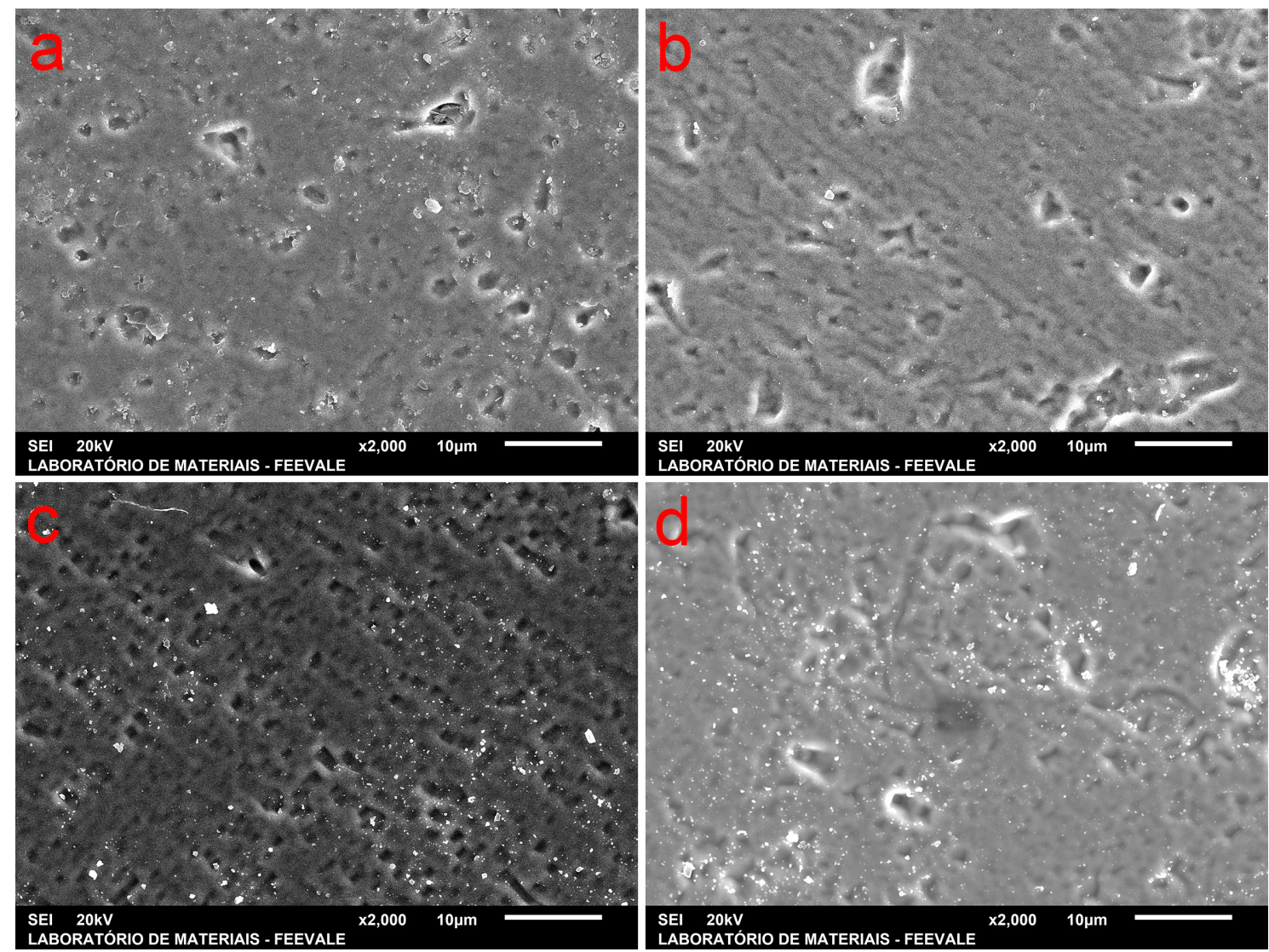

Figura 7. Micrografias obtidas ao MEV em vista de topo das amostras de nióbio anodizadas em licor pirolenhoso por tempos de (a) 300s; (b) 600s; (c) $1800 \mathrm{~s} ;$ e (d) $3600 \mathrm{~s}$.

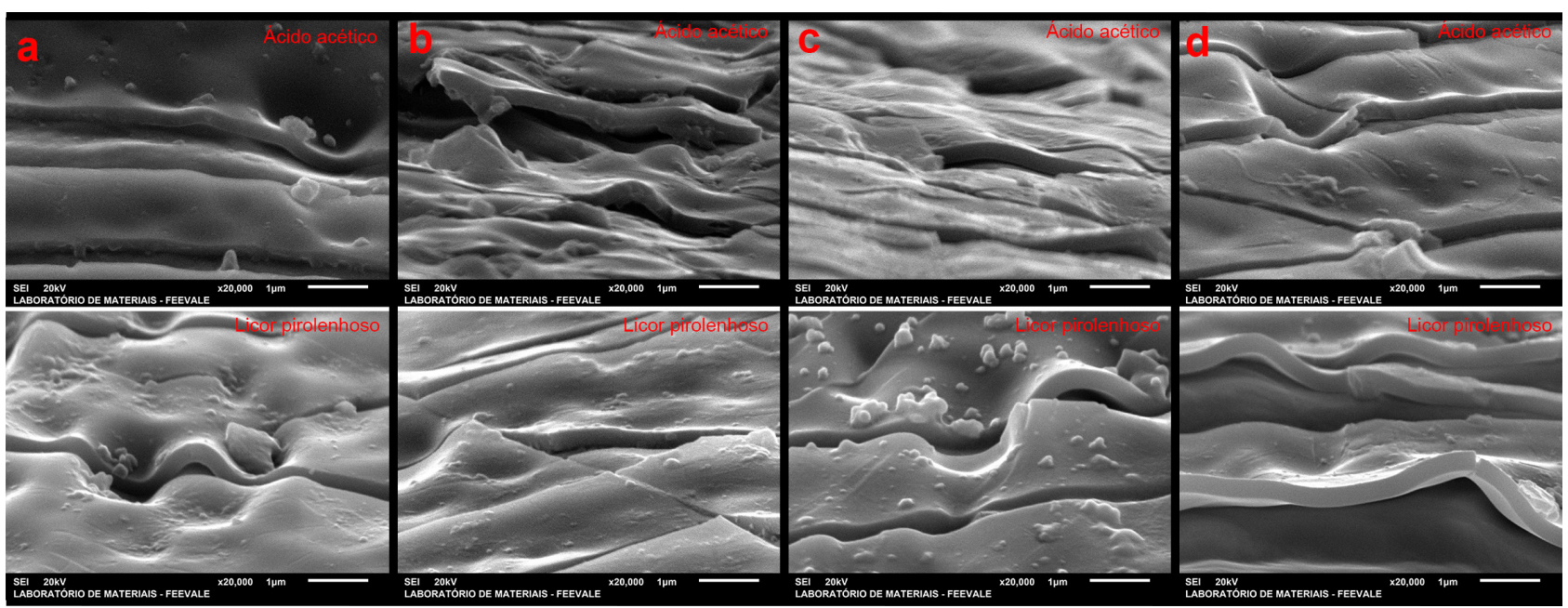

Figura 8. Micrografias obtidas ao MEV em vista de topo das amostras de nióbio anodizadas em licor pirolenhoso por tempos de (a) 300s; (b) 600s; (c) $1800 \mathrm{~s} ; \mathrm{e}$ (d) $3600 \mathrm{~s}$. 
o metal base. Além disso, as curvas de densidade de corrente apontam para a formação de óxido barreira. Como o licor contém compostos orgânicos e similares, deve-se também considerar que os defeitos superficiais observados, assemelhando-se a defeitos de porosidade, possa ocorrer possivelmente devido ao processo de dissolução durante a formação do óxido. A literatura mostra que o aumento destas imperfeições se dá com a elevação da densidade de corrente. No estudo realizado por Marcolin et al. [9] amostras de nióbio foram anodizadas em $1 \mathrm{~mol} / \mathrm{L}$ de ácido acético com aplicação de densidade de corrente de 10, 20 e $50 \mathrm{~mA} / \mathrm{cm}^{2}$ por $300 \mathrm{~s}$. Os autores observaram que o aumento da densidade de corrente provocava maior dissolução no óxido durante sua formação. Na amostra obtida em $10 \mathrm{~mA} /$ $\mathrm{cm}^{2}$ com aplicação de $100 \mathrm{~V}$ por $300 \mathrm{~s}$, os autores observaram, além de imperfeições, a formação de poros semelhantes a pites na superfície do nióbio.

Na Figura 8 são mostradas as secções transversais em ácido acético e licor pirolenhoso, respectivamente.

Observam-se nas Figura 8 que os óxidos se apresentam uniformes e contínuos, com uma espessura homogênea, característico da formação de óxido barreira. A partir das imagens de secção transversal dos óxidos (Figura 8) foram feitas medidas da espessura desses óxidos, as quais estão mostradas na Tabela 4.

De acordo com a Tabela 4, para as amostras Nb300, observa-se que a amostra contendo ácido acético apresenta menor espessura do que aquela anodizada em licor pirolenhoso. Isso pode ser devido ao maior $\partial \mathrm{V} / \partial \mathrm{t}$ observado na Tabela 3

Tabela 4. Espessuras dos óxidos de nióbio obtidos em ácido acético e licor pirolenhoso em tempos de 300, 600, 1800 e 3600 s

\begin{tabular}{ccc}
\hline Amostra & Ácido acético (nm) & Licor pirolenhoso (nm) [1] \\
\hline $\mathrm{Nb} 300$ & $251 \pm 12,3$ & $283 \pm 17$ \\
$\mathrm{Nb} 600$ & $299 \pm 14,8$ & $290 \pm 9$ \\
$\mathrm{Nb} 1800$ & $278 \pm 8,9$ & $285 \pm 24$ \\
$\mathrm{Nb} 3600$ & $282 \pm 13,0$ & $303 \pm 12$ \\
\hline
\end{tabular}

em ácido acético. Neste caso, o óxido deveria se formar mais rápido, com maior espessura, porém com maior quantidade de defeitos estequiométricos em comparação à amostra obtida em licor pirolenhoso [12,13].

Com o aumento do tempo de anodização, observa-se uma leve tendência ao aumento de espessura nos dois eletrólitos. Esse comportamento concorda com o aumento da intensidade da coloração observada com o aumento do tempo de anodização em estudo, indicando uma diminuição na quantidade de defeitos estequiométricos originados durante a formação do óxido [14]. No entanto, apesar da leve tendência ao aumento de espessura, observa-se que as espessuras se aproximam de valores de 300nm. Com isso, pode-se dizer que nas condições de anodização, a coloração rosa formada por anodização barreira em eletrólitos contendo ácido acético apresenta espessura aproximada de 300nm.

\section{Conclusões}

As amostras anodizadas em ácido acético e licor pirolenhoso apresentam duas regiões distintas de crescimento de óxido, o que foi atribuído à incorporação de íons acetato na superfície do metal, dificultando a migração de oxigênio para a formação de óxido.

Pelos resultados obtidos observou-se que os óxidos apresentaram coloração rosa em eletrólitos nas condições de anodização deste trabalho. Essa coloração ficou mais intensa, o que foi atribuído à diminuição de defeitos estequiométricos com o tempo de anodização. Essa coloração foi associada a uma espessura aproximada de 300nm.

Já as morfologias das amostras anodizadas nos dois eletrólitos apresentam os defeitos superficiais na superfície, as quais podem ser provenientes do ataque químico anterior ao processo de anodização. Portanto, os resultados obtidos mostram semelhanças nas amostras de nióbio anodizadas nos dois eletrólitos, o que indica que a anodização de nióbio em licor pirolenhoso é possivelmente governada pela quantidade de ácido acético presente no eletrólito.

\section{Referências}

1 Alves M, Cazetta JO, Nunes MA, Oliveira CAL, Colombi CA. Ação de diferentes preparações de extrato pirolenhoso sobre brevipalpus phoenicis (GEIJSKES). Revista Brasileira de Fruticultura. 2007;29(2):382-385.

2 Sá IM, Mueller LT, Moura ABD, Fuhr LT, Kunste SR, Oliveira CT. Anodização de nióbio em licor pirolenhoso. In: Anais do $38^{\circ}$ Congresso Brasileiro de Corrosão (INTERCORR); 2018; São Paulo. São Paulo: USP; 2018.

3 Shi P, Cheng FT, Man HC. Improvement in corrosion resistance of NiTi by anodization in acetic acid. Materials Letters. 2007;61(11-12):2385-2388.

4 Bianchin ACV, Maldaner GR, Fuhr LT, Beltrami LVR, Malfatti CF, Rieder ES, et al. A model for the formation of niobium structures by anodization. Materials Research. 2017;20(4):1010-1023.

5 Choi J, Lim JH, Lee SC, Chang JH, Kim KJ, Cho MA. Porous niobium oxide films prepared by anodization in HF/ $\mathrm{H}_{3} \mathrm{PO}_{4}$. Electrochimica Acta. 2006;51(25):5502-5507.

6 Karlinsey RL. Preparation of self-organized niobium oxide microstructures via potentiostatic anodization. Electrochemistry Communications. 2005;7(12):1190-1194. 
7 Komatsu I, Aoki H, Ebisawa M, Kuroda A, Kuroda K, Maeda S. Color change mechanism of niobium oxide thin film with incidental light angle and applied voltage. Thin Solid Films. 2016;603:180-186.

8 Karambakhsh A, Afshar A, Ghahramani S, Malekinejad P. Pure commercial titanium color anodizing and corrosion resistance. Journal of Materials Engineering and Performance. 2011;20(9):1690-1696.

9 Marcolin P, Longhi M, Caio L, Zini LP, Beltrami LVR, Silva JC, et al. Obtaining niobium oxides in acetic acid with addition of HF. Tecnologica em Metalurgia, Materiais e Mineração. 2018;15(1):35-42.

10 Narayanan R, Kwon TY, Kim $\mathrm{KH}$. TiO nanotubes from stirred glycerol/ $\mathrm{NH}_{4} \mathrm{~F}$ electrolyte: roughness, wetting behavior and adhesion for implant applications. Materials Chemistry and Physics. 2009;117(2-3):460-464.

11 Nico C, Monteiro T, Graça MPF. Niobium oxides and niobates physical properties: Review and prospects. Progress in Materials Science. 2016;80:1-37.

12 Wan J, Yan X, Ding J, Wang M, Hu K. Self-organized highly ordered $\mathrm{TiO}_{2}$ nanotubes in organic aqueous system. Materials Characterization. 2009;60(12):1534-1540.

13 Sui JH, Cai W. Formation of $\mathrm{ZrO}_{2}$ coating on the NiTi alloys for improving their surface properties. Nuclear Instruments and Methods in Physics Research. 2006;251(2):402-406.

14 Xing J, Xia Z, Hu J, Zhang Y, Zhong L. Time dependence of growth and crystallization of anodic titanium oxide films in potentiostatic mode. Corrosion Science. 2013;75:212-219.

Recebido em: 19 Mar. 2020

Aceito em: 30 Out. 2020 